\title{
Depression among Medical Staff during the Coronavirus Disease-19 Pandemic in Egypt: A Comparative Web-Based Cross-Sectional Study
}

\author{
Noha M. Elghazally (iD, Doaa Abdeldaim* \\ Department of Public Health and Community Medicine, Faculty of Medicine, Tanta University, Tanta, Egypt
}

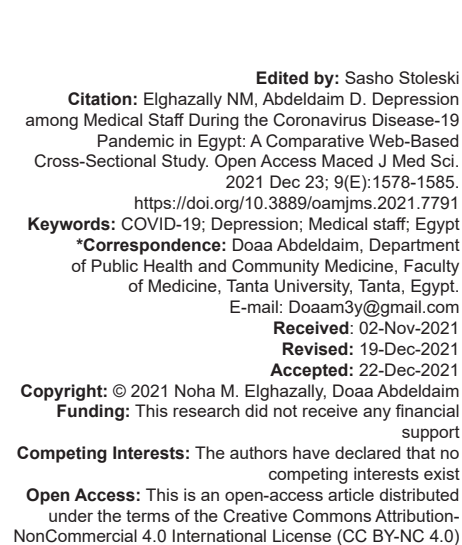

\section{Introduction}

On March 12, 2020, the World Health Organization (WHO) declared the coronavirus disease (COVID-19) as a pandemic with reporting approximately $4,628,903$ confirmed cases and 312,009 deaths [1]. The number of cases and deaths is rising rapidly, and created unexpected social, economic, and psychological devastation for both individuals and communities. The worldwide impact of this crisis is comparable with war [2]. The COVID-19 outbreak4 and subsequent global spread had created several challenges for health care workers and public worldwide. That pandemic leads to a high rate of mental health disorders across the globe [3]. The spread of infection has created a panic mode in the community as acute stress, anxiety, and depression in vulnerable individuals [3]. Risk factors such as long periods of social isolation, fear of unemployment, economic losses due to closure and death of family members are proposed to exacerbate self-destructive behavior of this pandemic [4].

Moreover, COVID-19 can cause neurological manifestations, including headache, impaired sense of smell and taste, agitation, delirium, and meningoencephalitis [5], [6]. Global infectious diseases have immediate and prolonged effect on the mental health of healthcare workers (HCWs) as during COVID-19 pandemic or previous international health crises such as severe acute respiratory syndrome and Middle East respiratory syndrome. Frontline health care workers who are involved in direct diagnosis, treatment, and care of patients with COVID-19 showed higher levels of symptoms of anxiety, insomnia, depression, and distress [7]. Global infectious diseases have immediate and prolonged effect on the mental health of HCWs as during COVID-19 pandemic. Health care workers who were isolated or working in high-risk locations had 2-3 times higher risk of posttraumatic stress [8]. There are many reasons behind mental health problems such as increasing number of confirmed and suspected cases, overwork, decline of personal protective equipment, widespread media coverage, lack of certain drugs, fear of infection for themselves and their families, caring for severing ill patients, caring for colleagues who have also become ill, and multiple losses [9], [10], [11], [12]. Hence, psychological support among health care workers is a critical part of the public health response. The WHO has published brief messages related to mental health and 
the importance of psychological first aid, it can be done through protecting the physical well-being of physicians and supporting the families of physicians [13], [14].

At present, many countries in the Eastern Mediterranean Region have started implementing activities and developing mental health programs as part of their national response to the COVID-19 pandemic [15]. On March 31, 2020, Egypt's Health Ministry announced the establishment of two hotlines (080-8880700 and 0220816831) to provide citizens with psychological support during the coronavirus pandemic; that was done with the help of 150 mental health professionals who had received online training for remote communication and provide psychological aid to the treatment teams at the isolation hospitals and other community groups [16]. It later expanded this service by appointing psychiatrists in all quarantine hospitals to provide specialized psychological care to patients with COVID19, healthcare personnel and people with mental health conditions [16].

This present study aimed to determine depression levels of physicians who work in isolation hospitals that treat patients with COVID-19 and those with other health facilities in Egypt during COVID-19 pandemic. Besides, to explore risk factors for depression were determined and interpreted to provide further psychological interventions for health care workers.

\section{Materials and Methods}

\section{Study design and participants}

This cross-sectional web-based study was conducted from 1 to May 15, 2020. The target population included Egyptian physicians from 27 governorates and autonomous regions were invited to participate in an online survey. In total, 2331 health care workers respond to the survey. Based on workplace of the participants, they were divided into two groups: group I: physicians who work in health facilities in Egypt other than isolation hospitals (second line); group $\Pi$ : physicians who work in isolation hospitals (Frontline physicians). The specified inclusion criteria were as follows: (1) Egyptian physicians; (2) confirming that they work in health facilities in Egypt. Furthermore, the exclusion criteria comprised the followings: (1) Physicians with any nationality other than Egyptian; (2) those who were on vacation while studying.

\section{Measures}

A self-administered questionnaire was designed for data collection. It was developed on the basis of literature and statistical experts in our college evaluated its validity and reliability (Cronbach's $\alpha \geq 0.70)$. This 19 -item questionnaire consisted of three sections:

\section{Section one}

This section comprises seven items; it is mainly focused on participants' characteristics including age, gender, marital status, residence, the type of job, years of experience, and presence of non-communicable diseases.

\section{Section two}

This section evaluated participants experiences of exposure to COVID-19-related events in their lives; whether there had confirmed COVID-19 cases in families or friends, whether they had been directly contact with confirmed or suspected COVID-19 patients, or whether they got infected with COVID-19 (3 questions).

\section{Section three}

This section included a 9-item Patient Health Questionnaire (PHQ-9) to assess depression levels among participants. The PHQ-9 is the depression module, which scores each of the 9 DSM-IV criteria as "0" (not at all) to "3" (nearly every day). The PHQ-9 score of $\geq 10$ had a sensitivity of $88 \%$ and a specificity of $88 \%$ for major depression. The scores of $5,10,15$, and 20 represented mild, moderate, moderately severe, and severe depression, respectively [17].

\section{Procedure}

Data collected through an online selfadministered questionnaire using Google forms with a consent form included with it. The link to the questionnaire was sent through emails, WhatsApp groups, Facebook groups, and other social media. The participants were encouraged to pass the survey to many people as possible. Once receiving and clicking on the link the participants will be directed to the objectives of the study and informed consent. After they accept taking the survey, they will fill up the demographic details. Then, a set of several questions will appear consecutively, in which the participants will answer.

\section{Statistical analysis}

The data analysis was performed using Statistical Package for the Social Sciences IBM Chicago, version 23. Depression and its associated factors among health care workers during the COVID-19 pandemic were considered as the outcome variable. Comparison of study variables was performed using independent 
sample t test and chi-square test. Explanatory variables included demographics, marriage history, and effects of COVID-19 related data. Each explanatory variable was divided into categories, and each observation will be presented as frequency number and percentage. The level of significance adopted was $p<0.05$.

\section{Results}

Table 1 presented the sociodemographic data and COVID-19 related events of study groups. The sample included 2331 physicians; 1177 of whom worked in front line hospitals (group II) and the remaining 1154 physicians (group I) in other health facilities (second line). The mean age of the participants is $34.3 \pm 6.1$ years. The majority of participants in group I and group II were in age group between 30 and 40 years (70.6\% and $55 \%$, respectively). In both groups, the majority of participants were females, married, urban dwellers, and specialists. The most common years of experience in groups I were $6-10$ years $(48.4 \%)$ and $1-5$ years in group II (46.5\%) with a mean of 6.8 years for all participants. Comorbidities affected insignificant percentage of both groups $(3.7 \%) .5 .3 \%$ of those in group II had confirmed cases in their families or among their friends. There was a high frequency of direct contact with confirmed or suspected patients in group II $(97.8 \%)$ and $56.3 \%$ in group I. In Groups I and II, only a small percentage of physicians $(1.7 \%$ and $3.8 \%$, respectively) were infected.

Table 2 demonstrated the prevalence of depressive symptoms and severity among the study groups for several days. Groups I and II were uninterested in doing things (51.3\% and $43.7 \%$ respectively). Almost the same proportion in both groups felt down, depressed or hopeless (45.3\% and $46.3 \%$ ). In group I and group II ( $45.1 \%$ and $40.1 \%$ respectively) were at risk of falling or staying asleep or sleeping excessively. Approximately, half of the people in group I and II (45.9\% and 50.6\%, respectively) were tired or had little energy. More than one- third of those in Groups I and II (35.2\% and 35.5\%, respectively) didn't have a poor appetite or overeating. Moreover, $41.3 \%$ of responders in group I and $40.2 \%$ in group II felt bad about themselves and their families.

On the other hand, nearly two fifths of those in group I and II (44.5\% and 40.5\%, respectively) had no trouble in the concentration on things at all. Furthermore, more than two thirds of those in Group I $(68.9 \%)$ and $61.1 \%$ of those in Group II didn't speak or move as slowly as usual. $91.4 \%$ of those in group I and $78.8 \%$ of those in group II had no thoughts of death or self-harm. Nearly one-third of those in groups I and II (31.2\% and $32.9 \%$, respectively) had mild depressive symptoms, while $5.1 \%$ in Groups I and $14.6 \%$ in group II had severe ones.

The mean total score for the group I was 8.3 and 9.8 for group II with a significant difference between the two groups. Association between total

Table 1: Distribution of sociodemographic data and COVID-19 related events in the lives of studied groups

\begin{tabular}{|c|c|c|c|c|}
\hline \multirow[t]{2}{*}{ Sociodemographic data } & Overall $(n=2331)$ & Group I $(n=1154)$ & Group II $(n=1177)$ & \multirow[t]{2}{*}{$p$-value } \\
\hline & Mean \pm SD/n (\%) & Mean \pm SD $/ n(\%)$ & Mean \pm SD $/ \mathrm{n}(\%)$ & \\
\hline \multicolumn{5}{|l|}{ Age groups } \\
\hline 20 & $507(21.8)$ & $194(16.8)$ & $313(26.6)$ & \multirow[t]{3}{*}{$0.0001^{*}$} \\
\hline 30 & $1462(62.7)$ & $815(70.6)$ & $647(55)$ & \\
\hline $50-60$ year & $59(2.5)$ & $21(1.8)$ & $38(3.2)$ & \\
\hline Age (years) & $34.3 \pm 6.1$ & $34.5 \pm 5.5$ & $34.2 \pm 6.7$ & 0.3 \\
\hline \multicolumn{5}{|l|}{ Sex } \\
\hline Male & $366(15.7)$ & $213(18.5)$ & $153(13)$ & \multirow[t]{2}{*}{$0.0001^{*}$} \\
\hline Female & $1965(84.3)$ & $941(81.5)$ & $1024(87)$ & \\
\hline Single & $793(34)$ & $233(20.2)$ & $560(47.6)$ & \multirow[t]{3}{*}{$0.0001^{*}$} \\
\hline Married & $1486(63.7)$ & 901 (78.1) & $585(49.7)$ & \\
\hline Divorced/widow & $52(2.3)$ & $20(1.7)$ & $32(2.7)$ & \\
\hline \multicolumn{5}{|l|}{ Residence } \\
\hline Urban & $1661(71.3)$ & $790(68.5)$ & $871(74)$ & \multirow[t]{2}{*}{$0.003^{*}$} \\
\hline Rural & $670(28.7)$ & $364(31.5)$ & $306(26)$ & \\
\hline \multicolumn{5}{|l|}{ Type of job } \\
\hline Resident & $462(19.8)$ & $205(17.8)$ & $257(21.8)$ & \multirow[t]{3}{*}{$0.04^{\star}$} \\
\hline Specialist & $1698(72.8)$ & $867(75.1)$ & $831(70.6)$ & \\
\hline Consultant & $171(7.3)$ & $82(7.1)$ & $89(7.6)$ & \\
\hline $6-10$ year & $985(42.3)$ & $558(48.4)$ & $427(36.3)$ & \\
\hline $11-15$ year & $268(11.5)$ & $107(9.3)$ & $161(13.7)$ & \\
\hline $16-20$ year & $28(1.2)$ & $13(1.1)$ & $15(1.3)$ & \\
\hline$>21$ year & $39(1.7)$ & $12(1)$ & $27(2.3)$ & \\
\hline \multicolumn{5}{|l|}{ Suffer from comorbidities } \\
\hline Yes & $87(3.7)$ & $35(3)$ & $52(4.4)$ & \multirow[t]{2}{*}{0.8} \\
\hline No & $2245(96.3)$ & $1119(97)$ & $1125(95.6)$ & \\
\hline \multicolumn{5}{|c|}{ Whether there had been confirmed COVID-19 cases in families or friends? } \\
\hline Yes & $92(3.9)$ & $30(2.5)$ & $62(5.3)$ & \multirow[t]{2}{*}{$0.001^{*}$} \\
\hline No & $2239(96.1)$ & $1124(97.4)$ & $1115(94.3)$ & \\
\hline \multicolumn{5}{|c|}{ Whether you had been directly contact with confirmed or suspected } \\
\hline \multicolumn{5}{|l|}{ COVID-19 patients? } \\
\hline Yes & $1801(77.3)$ & $650(56.3)$ & $1151(97.8)$ & \multirow[t]{2}{*}{$0.0001^{*}$} \\
\hline No & $530(22.7)$ & $504(43.7)$ & $26(2.2)$ & \\
\hline \multicolumn{5}{|c|}{ Whether you infected with COVID-19? } \\
\hline Yes & $65(2.8)$ & $20(1.7)$ & $45(3.8)$ & \multirow[t]{2}{*}{$0.002^{*}$} \\
\hline No & $2266(97.2)$ & $1134(98.3)$ & $1132(96.2)$ & \\
\hline
\end{tabular}


depression score and sociodemographic data of participants are shown in Table 3. Age, sex, marital status, occupation, years of experience, a kind of job, presence of confirmed cases in families or friends, and direct contact with confirmed or suspected cases all had statistically significant differences with the prevalence of depressive symptoms. $31 \%$ of those aged $40-50$ had mild depressive symptoms, while $43.1 \%$ of those aged 50-60 had moderate depressive symptoms. In terms of gender, $33.7 \%$ of males and $31.8 \%$ of females had mild depression. Furthermore, $27.7 \%$ of single participants and $34.8 \%$ of married participants had mild depression, while $38.5 \%$ of divorced and widowed participants had moderate depression. $31.8 \%$ of first line physicians had mild depression but $11.8 \%$ was severely depressed. The same was true for the second line physicians with $31.2 \%$ having mild symptoms and only $5.1 \%$ having severe ones. There was no difference in residence between both groups with $32.2 \%$ and $31.8 \%$ of urban and rural residents suffering from mild depression, respectively. $38.2 \%$ of physicians with few years of experience (1-5 years) suffered from mild depression. Residents and specialists $(39.4 \%$ and $31 \% 9$, respectively) showed mild depression, while consultants $(27.1 \%)$ showed moderate depression. Regarding the presence of comorbidities, $38 \%$ of those with comorbidity had mild depression. Furthermore, $38 \%$ of physicians who had confirmed COVID-19 cases in their families and friends and $33.6 \%$ who had direct contact with confirmed or suspected COVID-19 patients noticed with mild depression. $30.8 \%$, who were infected with COVID-19 experienced mild depression.

\section{Discussion}

Epidemiological studies have reported that during disease pandemics, HCWs at the frontline

Table 2: Prevalence of depressive symptoms among the studied groups

\begin{tabular}{|c|c|c|c|}
\hline PHQ-9 items & Group I (n = 1154) n (\%) & Group II (n = 1177) n (\%) & $\mathrm{X}^{2} / \mathrm{t} \mathrm{P}$ value \\
\hline \multicolumn{4}{|l|}{ Little interest or pleasure in doing things: } \\
\hline Not at all & $168(14.6)$ & $190(16.1 \%)$ & 19.1 \\
\hline Several days & $592(51.3)$ & $514(43.7 \%)$ & $0.0001^{*}$ \\
\hline More than half the days & $172(14.9)$ & $170(14.4 \%)$ & \\
\hline Nearly every day & $222(19.2)$ & $303(25.7 \%)$ & \\
\hline \multicolumn{4}{|l|}{ Feeling down, depressed or hopeless: } \\
\hline Not at all & $269(23.3)$ & $210(17.8 \%)$ & 26 \\
\hline Several days & $523(45.3)$ & $545(46.3 \%)$ & $0.0001^{*}$ \\
\hline More than half the days & $220(19.1)$ & $200(17 \%)$ & \\
\hline Nearly every day & $142(12.3)$ & $222(18.9 \%)$ & \\
\hline \multicolumn{4}{|c|}{ Trouble falling or staying asleep or sleeping too much: } \\
\hline Not at all & $420(36.4)$ & $240(20.4 \%)$ & 106.4 \\
\hline Several days & $463(40.1)$ & $531(45.1 \%)$ & $0.0001^{*}$ \\
\hline More than half the days & $162(14)$ & $160(13.6 \%)$ & \\
\hline Nearly every day & $109(9.4)$ & $246(20.9 \%)$ & \\
\hline \multicolumn{4}{|l|}{ Feeling tired or having little energy: } \\
\hline Not at all & $243(21.1)$ & $183(15.5 \%)$ & 12.8 \\
\hline Several days & $530(45.9)$ & $596(50.6 \%)$ & $0.005^{*}$ \\
\hline More than half the days & $183(15.9)$ & $183(15.5 \%)$ & \\
\hline Nearly every day & $198(17.2)$ & $215(18.3 \%)$ & \\
\hline \multicolumn{4}{|l|}{ Poor appetite or overeating: } \\
\hline Not at all & $406(35.2)$ & $418(35.5 \%)$ & 19.2 \\
\hline Several days & $381(33)$ & $356(30.2 \%)$ & $0.0001^{*}$ \\
\hline More than half the days & 219 (19) & $181(15.4 \%)$ & \\
\hline Nearly every day & $148(12.8)$ & $222(18.9 \%)$ & \\
\hline \multicolumn{4}{|c|}{$\begin{array}{l}\text { Feeling bad about yourself-or that you are failure or have let yourself or } \\
\text { your family down: }\end{array}$} \\
\hline Not at all & $439(38)$ & $422(35.9)$ & 33 \\
\hline Several days & $477(41.3)$ & $473(40.2)$ & $0.0001^{*}$ \\
\hline More than half the days & $141(12.2)$ & $100(8.5)$ & \\
\hline Nearly every day & $97(8.4)$ & $182(15.5)$ & \\
\hline \multicolumn{4}{|c|}{$\begin{array}{l}\text { Trouble concentrating on things, such as reading newspaper or watching } \\
\text { television: }\end{array}$} \\
\hline Not at all & $513(44.5)$ & $480(40.8)$ & 45.5 \\
\hline Several days & $420(36.4)$ & $334(28.4)$ & $0.0001^{*}$ \\
\hline More than half the days & $111(9.6)$ & $191(16.2)$ & \\
\hline Nearly every day & $110(9.5)$ & $172(14.6)$ & \\
\hline \multicolumn{4}{|c|}{$\begin{array}{l}\text { Moving or speaking so slowly. Or the opposite-being so aggressive or } \\
\text { agitated that you have been moving around a lot more than usual }\end{array}$} \\
\hline Not at all & 795 (68.9) & $719(61.1)$ & 47.5 \\
\hline Several days & $271(23.5)$ & $258(21.9)$ & $0.0001^{*}$ \\
\hline More than half the days & 39 (3.4) & $90(7.6)$ & \\
\hline Nearly every day & $49(4.2)$ & $110(9.3)$ & \\
\hline \multicolumn{4}{|c|}{ Thought that you would be better off dead or of hurting yourself: } \\
\hline Not at all & $1055(91.4)$ & $927(78.8)$ & 98.7 \\
\hline Several days & $59(5.1)$ & $130(11)$ & $0.0001^{*}$ \\
\hline More than half the days & $30(2.6)$ & $120(10.2)$ & \\
\hline Nearly every day & $10(0.9)$ & $0(0)$ & \\
\hline \multirow[t]{2}{*}{ Total depression scores (Mean \pm SD) } & $8.3 \pm 5.6$ & $9.8 \pm 7.1$ & 5.9 \\
\hline & & & $0.01^{*}$ \\
\hline \multicolumn{4}{|l|}{ Severity of depression } \\
\hline No depressive symptoms & $30(2.6)$ & $20(1.7)$ & 68.4 \\
\hline Minimal depression & $332(28.8)$ & $284(24.1)$ & $0.001^{*}$ \\
\hline Mild depression & $360(31.2)$ & $387(32.9)$ & \\
\hline Moderate depression & $282(24.5)$ & 224 (19) & \\
\hline Moderately severe depression & $90(7.8)$ & $90(7.9)$ & \\
\hline Severe depression & $59(5.1)$ & $172(14.6)$ & \\
\hline
\end{tabular}


who combats illness are vulnerable to stress, which may lead to depression [18]. In this present study, we assessed depression levels and analyzed independent risk factors during the COVID-19 pandemic.

Short-term depressive symptoms among HCWs caring for patients infected during a pandemic were as anxiety, while depression felt by healthcare workers in long-term [19]. Similarly, workers caring for patients during the Ebola outbreak also experienced both anxiety and depression [20]. The prevalence of depression in the current study was recorded by using $\mathrm{PHQ}-9$ among both groups; nearly one third of group I and II (31.2\% and $32.9 \%$, respectively) had mild depressive symptoms, whereas $5.1 \%$ in group I and $14.6 \%$ in group II had severe ones, with the statistically significant difference between them. The total measured depression scores were significantly higher among group II than I $(9.8 \pm 7.1$ vs. $8.3 \pm 5.6)$. The nearby results found by Kang et al., in Wuhan, reported $36.9 \%$ subthreshold mental health disturbances, $34.4 \%$ mild disorders,

Table 3: Association between total depression score and sociodemographic data of studied groups

\begin{tabular}{|c|c|c|c|c|c|c|}
\hline \multirow[t]{2}{*}{ Variable } & \multicolumn{6}{|c|}{ PHQ-9 depressive symptoms } \\
\hline & $\begin{array}{l}\text { No depressive } \\
\text { symptoms (\%) }\end{array}$ & $\begin{array}{l}\text { Minimal } \\
\text { depression (\%) }\end{array}$ & Mild depression & $\begin{array}{l}\text { Moderate } \\
\text { depression }\end{array}$ & $\begin{array}{l}\text { Moderately severe } \\
\text { depression }\end{array}$ & $\begin{array}{l}\text { Severe } \\
\text { depression }\end{array}$ \\
\hline \multicolumn{7}{|l|}{ Age group } \\
\hline 20 & $4(0.8)$ & $125(24.7)$ & $170(33.5)$ & $98(19.3)$ & $45(8.9)$ & $65(12.8)$ \\
\hline 40 & $12(4)$ & $94(31)$ & $80(26.4)$ & $42(13.9)$ & $24(7.9)$ & $51(16.8)$ \\
\hline $50-60$ year & $10(17.2)$ & $10(17.2)$ & $5(8.6)$ & $25(43.1)$ & $0(0)$ & $8(13.8)$ \\
\hline $\mathrm{X}^{2}, \mathrm{p}$-value & $150.7,0.0001^{*}$ & & & & & \\
\hline Effect size & 0.005 & & & & & \\
\hline \multicolumn{7}{|l|}{ Sex } \\
\hline Female & $20(1)$ & $48(24.8)$ & $624(31.8)$ & $433(22)$ & $170(8.7)$ & $231(11.8)$ \\
\hline $\mathrm{X}^{2}, \mathrm{p}$-value & $145.2,0.0001^{*}$ & & & & & \\
\hline \multirow{2}{*}{\multicolumn{7}{|c|}{ Marital status }} \\
\hline & & & & & & \\
\hline Single & $10(1.3)$ & $180(22.7)$ & $220(27.7)$ & $123(15.5)$ & $120(15.1)$ & $140(17.7)$ \\
\hline Married & $40(2.7)$ & $426(28.7)$ & $517(34.8)$ & $363(24.4)$ & $60(4)$ & $79(5.3)$ \\
\hline Divorced/Widow & $0(0)$ & $10(19.2)$ & $10(19.2)$ & $20(38.5)$ & $0(0)$ & $12(23.1)$ \\
\hline$X^{2}, p$-value & $255.9,0.0001^{*}$ & & & & & \\
\hline Effect size & 0.04 & & & & & \\
\hline \multicolumn{7}{|l|}{ Occupation } \\
\hline$X^{2} p$-value & $68.4,0.0001^{*}$ & & & & & \\
\hline Effect size & 0.02 & & & & & \\
\hline \multicolumn{7}{|l|}{ Residence } \\
\hline Urban & $34(2)$ & $439(26.4)$ & $534(32.2)$ & $363(21.9)$ & $123(7.4)$ & $167(10.1)$ \\
\hline Rural & $16(2.4)$ & $177(26.4)$ & $213(31.8)$ & $143(21.3)$ & $57(8.5)$ & $64(9.6)$ \\
\hline $\mathrm{X}^{2}, \mathrm{p}$-value & $1.2,0.9$ & & & & & \\
\hline \multirow{2}{*}{\multicolumn{7}{|c|}{ Years of experience }} \\
\hline & & & & & & \\
\hline $1-5 y$ & $15(1.5)$ & $233(23)$ & $386(38.2)$ & $185(18.3)$ & $102(10.1)$ & $90(8.9)$ \\
\hline $6-10 y$ & $16(1.6)$ & $294(29.8)$ & $280(28.4)$ & $255(25.9)$ & $55(5.6)$ & $85(8.6)$ \\
\hline $11-15 y$ & $9(3.4)$ & $75(28)$ & $73(27.2)$ & $41(15.3)$ & $22(8.2)$ & $48(17.9)$ \\
\hline $16-20 y$ & $7(25)$ & $6(21.4)$ & $6(21.4)$ & $5(17.9)$ & $1(3.6)$ & $3(10.7)$ \\
\hline$>21 y$ & $3(7.9)$ & $8(21.1)$ & $2((5.3)$ & $20(52.6)$ & $0(0)$ & $5(13.2)$ \\
\hline$X^{2}, p$ & $188.6,0.000^{*}$ & & & & & \\
\hline Effect size & 0.02 & & & & & \\
\hline \multicolumn{7}{|l|}{ Type of job } \\
\hline Resident & $15(3.2)$ & $119(25.8)$ & $182(39.4)$ & $90(19.5)$ & $28(6.1)$ & $28(6.1)$ \\
\hline Specialist & $21(1.2)$ & $456(26.9)$ & $526(26.9)$ & $370(21.8)$ & $143(8.4)$ & $182(10.7)$ \\
\hline Consultant & $14(8.2)$ & $41(24.1)$ & 39 (22.9) & $46(27.1)$ & $9(5.3)$ & $21(12.4)$ \\
\hline$X^{2}, p$ & $68.2,0.0001^{*}$ & & & & & \\
\hline Effect size & 0.007 & & & & & \\
\hline Present & $47(2.1)$ & $588(26.2)$ & $729(32.5)$ & $486(21.7)$ & $174(7.8)$ & $220(9.8)$ \\
\hline$x^{2}, p$ & $6.4,0.3$ & & & & & \\
\hline Effect size & 0.0 & & & & & \\
\hline \multirow{3}{*}{\multicolumn{7}{|c|}{$\begin{array}{l}\text { Whether there had been } \\
\text { confirmed COVID-19 } \\
\text { cases in families or } \\
\text { friends? }\end{array}$}} \\
\hline & & & & & & \\
\hline Yes & $1(1.1)$ & $16(17.4)$ & $35(38)$ & $13(14.1)$ & & \\
\hline No & $49(2.2)$ & $600(26.8)$ & $712(31.8)$ & $493(22)$ & $172(7.7)$ & $212(9.5)$ \\
\hline$x^{2}, p$ & $18.3,0.003^{*}$ & & & & & \\
\hline Effect size & 0.002 & & & & & \\
\hline & & & & & & \\
\hline directly contact with & & & & & & \\
\hline confirmed or suspec & & & & & & \\
\hline COVID-19 patients? & & & & & & \\
\hline Yes & $20(1.1)$ & $466(25.9)$ & $605(33.6)$ & $382(21.2)$ & $135(7.5)$ & $193(10.7)$ \\
\hline No & $30(5.7)$ & $150(28.4)$ & $142(26.8)$ & $124(23.4)$ & $45(8.5)$ & $38(7.2)$ \\
\hline$x^{2}, p$ & $53,0.000^{*}$ & & & & & \\
\hline Effect size & 0.006 & & & & & \\
\hline Whether you infecte & & & & & & \\
\hline with COVID-19? & & & & & & \\
\hline Yes & $0(0)$ & $15(23.1)$ & $20(30.8)$ & $12(18.5)$ & $5(7.7)$ & $13(20)$ \\
\hline No & $50(2.2)$ & $601(26.5)$ & $727(32.1)$ & $494(21.8)$ & $175(7.7)$ & $218(9.6)$ \\
\hline$x^{2}, p$ & $8.9,0.1$ & & & & & \\
\hline Effect size & 0.001 & & & & & \\
\hline
\end{tabular}


$22.4 \%$ moderate disorders, and $6.2 \%$ severe disturbance among nursing staff [21].

Du et al. [22] also examined the psychosocial impact of COVID-19 among Wuhan and non-Wuhan frontline health care workers and revealed that $12.7 \%$ of them had at least mild depressive. Moreover, they reported more negative affective symptoms among Wuhan health care workers.

Zhang et al. [23] demonstrated signs of depression among Chinese medical workers. Another study among frontline health care workers in China found that depression appeared among $50.4 \%$ of them [24]. Hence, health care workers may be at higher risk of depression and anxiety than the general population during fighting against COVID-19 [10].

On contrary, Li et al. [25] conducted a study in Singapore and found that the frontline nurse had significantly lower rates of trauma than non-frontline nurses and the general population. Moreover, Liang et al. [26] showed that there was no significant difference in anxiety and depression scores among the staff in the COVID-19-related department and other departments. Reasons for this discrepancy might be related to the unavailability of psychological support and unavailability of information related to current pandemic. It was critical in current study to clarify the related factors that endanger the mental health of health care workers as these could be potential targets for intervention.

There was a significant difference in levels of depression among physicians in different age groups, with higher rates among those between 20 and 30 years old; also, female physicians had more rates of depression than males. Our findings were consistent with the results of Rossi et al. [27] who reported younger age and female sex are associated with higher levels of depression among health care workers. In this regard, the previous research suggested that females are more prone to depression, anxiety and psychological stress [28], [29], [30], [31].

Other factors significantly associated with depression in the current study were feeling lonely among HCWs either as divorced, widow or single, having concomitant chronic non-communicable diseases, having confirmed COVID-19 cases in families or friends, contacted directly with confirmed or suspected COVID-19 patients, or infected with COVID-19. Nearby results detected by Zhang et al. [23] showed that having disease currently or being in contact with COVID-19 patients in hospitals were considered common risk factors for depression symptoms among medical health workers in China.

In our study, health care workers with short years of experience (1-5 years) or those with specialty degrees reported higher rates of depression. The nearby results which were done by Lai et al. [24] in China showed that possessing an intermediate professional title was associated with higher levels of anxiety and depression. Moreover, RicciCabello et al. [32] explained that the occurrence of depression and other mental problems were linked to occupational factors, for example, working in a highrisk environment (frontline staff), and having lower levels of specialized training and job experience. These findings emphasize the importance of training as preparedness public health activities during pandemics as young physicians are the cornerstones in the fight.

\section{Limitations of the study}

This present study suffered from some methodological limitations. First, the findings could not be generalized to various cases since the sample size was small and participants were selected from a single geographic region. Second, cross-sectional studies mostly fail to specify a definite reason behind a correlation. This restriction might avoid a deep understanding of the essence of the causal relationship between study variables. As the third limitation, this study used self-report scales that can only identify the emotions of patients through the assessment and can't to reflect their real emotions. Hence, it is suggested that future studies should focus on methodological limitations, such as the sole reliance on self-report scales due to memory bias and demand characteristics, lack of empirical data, and disregarding ethnic and personality differences [33].

\section{Conclusions}

Our findings presented that symptom of depression are common among medical staff during the COVID-19 pandemic, especially frontline physicians, females, and younger age.

\section{Recommendations}

Health experts should start setting up multidisciplinary mental health teams at regional and national levels to deal with mental health problems and provide psychological support to health care workers. Workplace interventions that reduce stigma associated with mental illness and encourage support for colleagues experiencing psychological difficulties should be improved. Furthermore, regular evaluation of medical personnel involved in treatment and diagnosis of patients with COVID-19 must assess their stress, depression, and anxiety. 


\section{Ethical Approval}

The study was held subsequently upon approval of the Research Ethics Committee at Tanta Faculty of Medicine. A consent was attached to the Google form. It explained the type of study, objectives, and importance at the beginning of the survey link. The responders were informed that they can withdraw at any stage of the survey, and they were asked if they are fully willing to participate in this study before being enrolled. Confidentiality was assured for all participating individuals.

\section{Acknowledgment}

The authors like to thank all participants in our study.

\section{References}

1. World Health Organization. Available from: https://www.who.int/ docs/default-source/coronaviruse/situationreports/20200427sitrep-98-covid-19.pdf?sfvrsn=90323472 4 [Last accessed on 2020 Apr 27]

2. Wikipedia Contributors. List of Wars by Death Toll. Wikipedia. Available from: https://en.wikipedia.org/wiki/List_of_wars_by_ death_toll [Last accessed on 2020 Mar 26]

3. Mao L, Jin $\mathrm{H}$, Wang $\mathrm{M}, \mathrm{Hu} \mathrm{Y}$, Chen $\mathrm{S}, \mathrm{He} \mathrm{Q}$, et al. Neurologic manifestations of hospitalized patients with coronavirus disease 2019 in Wuhan, China. JAMA Neurol. 2020;77(6):683-90. https://doi.org/10.1001/jamaneurol.2020.1127 PMid:32275288

4. Wang C, Pan R, Wan X, Tan Y, Xu L, Ho CS, et al. Immediate psychological responses and associated factors during the initial stage of the 2019 coronavirus disease (COVID-19) epidemic among the general population in China. Int J Environ Res Public Health. 2020;17(5):1729. https://doi.org/10.3390/ ijerph17051729

PMid:32155789

5. Yao H, Chen JH, Xu YF. Patients with mental health disorders in the COVID-19 epidemic. Lancet Psychiatry. 2020;7(4):e21. https://doi.org/10.1016/S2215-0366(20)30090-0

PMid:32199510

6. Khosravi M. Candidate Psychotropics against SARS-CoV-2: A Narrative Review. Pharmacopsychiatry. 2021. https://doi. org/10.1055/a-1551-3756

PMid:34399430

7. Greenberg N. Managing mental health challenges faced by healthcare workers during covid-19 pandemic. BMJ. 2020;368:m1211. https://doi.org/10.1136/bmj.m1211 PMid:32217624

8. Kang L, Li Y, Hu S, Chen M, Yang C, Yang BX, et al. The mental health of medical workers in Wuhan, China dealing with the 2019 novel coronavirus. Lancet Psychiatry. 2020;7(3):e14.
https://doi.org/10.1016/S2215-0366(20)30047-X

PMid:32035030

9. Walton M, Murray E, Christian MD. Mental health care for medical staff and affiliated healthcare workers during the COVID-19 pandemic. Eur Heart J Acute Cardiovasc Care. 2020;9(3):241-7. https://doi.org/10.1177/2048872620922795 PMid:32342698

10. Khosravi M. Stress Reduction Model of COVID-19 Pandemic. Iran J Psychiatry Behav Sci. 2020;14(2):e103865. https://doi. org/10.5812/ijpbs.103865

11. Khosravi M. Worden's task-based model for treating persistent complex bereavement disorder during the coronavirus disease-19 pandemic: A narrative review. Open Access Maced J Med Sci. 2020;8(T1):553-9. https://doi.org/10.3889/ oamjms.2020.5502

12. Khosravi M. Worden's task-based approach for supporting people bereaved by COVID-19. Curr Psychol. 2021;1-2. https:// doi.org/10.1007/s12144-020-01292-0

PMid:33424200

13. World Health Organization. Mental Health and psychological consideration during the COVID-19 Outbreak. Geneva: World Health Organization; 2021. Available from: https://www.who. int/publications/i/item/WHO-2019-nCoV-MentalHealth-2020.1 [Last accessed on 2020 Mar 18].

14. Huang J, Liu F, Teng Z, Chen J, Zhao J, Wang X, Wu R. Care for the psychological status of frontline medical staff fighting against Coronavirus Disease 2019 (COVID-19). Clin Infect Dis. 2020;71(12):3268-9. https://doi.org/10.1093/cid/ciaa385 PMid:32246142

15. Khosravi M. COVID-19 quarantine: Two-way interaction between physical activity and mental health. Eur J Transl Myol. 2021;30(4):9509. https://doi.org/10.4081/ejtm.2020.9509 PMid:33520149

16. Egypt-Ministry of Health and Population (MOHP): COVID-19 (Corona virus Information). Available from: https:// socialprotection.org/connect/stakeholders/egypt-mohpministry-health-and-population [Last accessed on 2020 Apr 01].

17. Kroenke K, Spitzer RL, Williams JB. The PHQ-9: Validity of a brief depressionseveritymeasure.JGen InternMed.2001;16(9):606-13. https://doi.org/10.1046/j.1525-1497.2001.016009606.x

PMid: 11556941

18. Douglas AM, Marco AR. Prevalence of depression and depressive symptoms among resident physicians: A systematic review and meta-analysis. JAMA. 2015;314(22):2373-83. https://doi.org/10.1001/jama.2015.15845

PMid:26647259

19. Chong MY, Wang WC, Hsieh WC, Lee CY, Chiu NM, Yeh WC, et al. Psychological impact of severe acute respiratory syndrome on health workers in a tertiary hospital. $\mathrm{Br} \mathrm{J}$ Psychiatry. 2004;185:127-33. https://doi.org/10.1192/bjp.185.2.127 PMid: 15286063

20. McMahon SA, Ho LS, Brown H, Miller L, Ansumana R Kennedy CE. Healthcare providers on the frontlines: a qualitative investigation of the social and emotional impact of delivering health services during Sierra Leone's Ebola epidemic. Health Policy Plan. 2016;31(9):1232-9. https://doi.org/10.1093/heapol/ CZW055 PMid:27277598

21. Kang L, Ma S, Chen M, Yang J, Wang Y, Li R, et al. Impact on mental health and perceptions of psychological care among medical and nursing staff in Wuhan during the 2019 novel coronavirus disease outbreak: A cross-sectional study. Brain Behav Immun. 2020;87:11-7. https://doi.org/10.1016/j. bbi.2020.03.028

PMid:32240764 
22. Du J, Dong L, Wang T, Yuan C, Fu R, Zhang L, et al. Psychological symptoms among frontline healthcare workers during COVID-19 outbreak in Wuhan. Gen Hosp Psychiatry. 2020;67:144-5. https://doi.org/10.1016/j. genhosppsych.2020.03.011

PMid:32381270

23. Zhang WR, Wang $K$, Yin L, Zhao WF, Xue Q, Peng $M$, et al. Mental health and psychosocial problems of medical health workers during the COVID-19 epidemic in China Psychother Psychosom. 2020;89(4):242-50. https://doi. org/10.1159/000507639

PMid: 32272480

24. Lai J, Ma S, Wang Y, Cai Z, Hu J, Wei N, et al. Factors associated with mental health outcomes among health care workers exposed to coronavirus disease 2019. JAMA Netw Open. 2020;3(3):e203976. https://doi.org/10.1001/ jamanetworkopen.2020.3976 PMid:32202646

25. Li Z, Ge J, Yang M, Feng J, Qiao M, Jiang R, et al. Vicarious traumatization in the general public, members, and non-members of medical teams aiding in COVID-19 control. Brain Behav Immun. 2020;88:916-9. https://doi.org/10.1016/j.bbi.2020.03.007 PMid:32169498

26. Liang $Y$, Chen M, Zheng X, Liu J. Screening for Chinese medical staff mental health by SDS and SAS during the outbreak of COVID-19. J Psychosom Res. 2020;133:110102. https://doi. org/10.1016/j.jpsychores.2020.110102

PMid:32224344

27. Rossi R, Socci V, Pacitti F, Di Lorenzo G, Di Marco A, Siracusano A, et al. Mental health outcomes among frontline and second-line health care workers during the coronavirus disease 2019 (COVID-19) pandemic in Italy. JAMA Netw Open. 2020;3(5):e2010185. https://doi.org/10.1001/ jamanetworkopen.2020.10185

\section{PMid:32463467}

28. Maunder RG, Lancee WJ, Rourke S, Hunter JJ, Goldbloom D, Balderson $\mathrm{K}$, et al. Factors associated with the psychological impact of severe acute respiratory syndrome on nurses and other hospital workers in Toronto. Psychosom Med. 2004;66(6):938-42. https://doi.org/10.1097/01.psy.0000145673.84698.18

PMid: 15564361

29. Kessler RC, McGonagle KA, Zhao S, Nelson CB, Hughes M, Eshleman S, et al. Lifetime and 12-month prevalence of DSM-III-R psychiatric disorders in the United States: results from the National Comorbidity Survey. Arch Gen Psychiatry. 1994;51(1):8-19. https://doi.org/10.1001/archpsyc.1994.03950010008002 PMid:8279933

30. Kessler RC, Sonnega A, Bromet E, Hughes M, Nelson CB Posttraumatic stress disorder in the national comorbidity survey. Arch Gen Psychiatry. 1995;52(12):1048-60. https://doi. org/10.1001/archpsyc.1995.03950240066012 PMid:7492257

31. Kessler RC, Chiu WT, Demler O, Walters EE. Prevalence, severity, and comorbidity of 12-month DSM-IV disorders in the National Comorbidity Survey Replication. Arch Gen Psychiatry. 2005;62(6):617-27. https://doi.org/10.1001/archpsyc.62.6.617 PMid: 15939839

32. Serrano-Ripoll MJ, Meneses-Echavez JF, Ricci-Cabello I, FraileNavarro D, Fiol-deRoque MA, Pastor-Moreno G, et al. Impact of viral epidemic outbreaks on mental health of healthcare workers: A rapid systematic review and meta-analysis. J Affect Disord. 2020;277:347-57. https://doi.org/10.1016/j.jad.2020.08.034 PMid:32861835

33. Khosravi M. Neuroticism as a marker of vulnerability to COVID-19 Infection. Psychiatry Investig. 2020;17(7):710-1. https://doi.org/10.30773/pi.2020.0199

PMid:32654438 